\title{
LESÕES DA TRAQUÉIA E GRANDES BRÔNQUIOS
}

\author{
TRACHEAL AND MAJOR BRONCHIAL INJURIES
}

\author{
Giovanni Antonio Marsico, TCBC-RJ ${ }^{1}$ \\ Dirceo Edson de Azevedo, ACBC-R.' ${ }^{2}$ \\ Jorge Montessi ${ }^{3}$ \\ Antonio Miraldi Clemente ${ }^{4}$ \\ João Paulo Vieira ${ }^{5}$
}

\begin{abstract}
Resumo: As lesões traqueobrônquicas são raras, porém, no trauma de tórax, envolvem grande risco de vida. As suas manifestações são variáveis e não é incomum o diagnóstico ser protraído. O sucesso no diagnóstico e tratamento, freqüentemente, requer alto grau de suspeição e a correção cirúrgica como método de escolha. Após trauma fechado de tórax, a ruptura da traquéia e dos brônquios principais, geralmente, ocorre nas proximidades da carina. O rompimento da árvore traqueobrônquica, ocasionado por acidentes em alta velocidade, com alto impacto e grande liberação de energia, geralmente está associado a outras lesões. Os sinais comumente presentes são: enfisema subcutâneo, dispnéia e hemoptise. Os achados radiológicos mais comuns incluem pneumotórax, pneumomediastino, fraturas de costelas e clavícula. As broncoscopias efetivamente rígida e flexível são considerados métodos diagnósticos eficazes, desde que manuseados por cirurgião torácico treinado. O diagnóstico precoce deve ser enfatizado, pois evita as complicações associadas ao reparo tardio das lesões. O mecanismo etiológico, o diagnóstico e os aspectos da terapêutica na literatura mundial são revistos e discutidos.
\end{abstract}

Unitermos: Trauma de tórax; Lesões traqueobrônquicas; Lesões da traquéia e grandes brônquios.

\section{INTRODUÇÃO}

O primeiro relato de ruptura brônquica é atribuído a Seuvre, em 1873. Griffith publicou, em 1949, a primeira correção cirúrgica de uma ruptura total de brônquio, realizada dois meses após o trauma. Scannell, em 1955, operou com sucesso, na fase aguda, uma lesão brônquica. ${ }^{1,2,3,4}$

A incidência das lesões traqueobrônquicas, nos traumas de tórax, varia de $0,3 \%$ a $1 \%$. Bertelsen e Howitz ${ }^{5}$, analisando 1.178 óbitos ocorridos logo após o trauma, encontraram $33(2,8 \%)$ lesões traqueobrônquicas, com 27 $(81,8 \%)$ que tiveram morte imediata. Nos grandes centros urbanos de trauma, onde são realizadas de 2.500 a 3.000 admissões por ano, a expectativa é de que ocorram de duas a quatro lesões traqueobrônquicas anuais. ${ }^{6}$

Embora raras, as lesões da traquéia e grandes brônquios cursam com taxas de letalidade em torno de $30 \%$, principalmente quando o diagnóstico não é estabelecido de imediato. Mesmo quando a correção cirúrgica é reali-

1. Doutor em Cirurgia Setor Tórax da UFRJ. Cirurgião de Tórax do Hospital Geral do Andaraí - RJ. Ministério da Saúde, Cirurgião de Tórax do Instituto de Doenças do Tórax da Universidade Federal do Rio de Janeiro UFRJ

2. Chefe do Serviço de Cirurgia Torácica do Hospital Geral do Andaraí - RJ. Ministério da Saúde

3. Professor Adjunto e Chefe do Serviço de Cirurgia Torácica do Hospital Universitário da UFRJ. Cirurgião de Tórax do Instituto de Doenças do Tórax da UFRJ

4. Chefe do Serviço de Cirurgia Torácica do Hospital da Força Aérea do Galeão - RJ. Cirurgião de Tórax do Instituto de Doenças do Tórax da UFRJ

5. Professor Substituto de Cirurgia Torácica do Hospital Universitário da Universidade Federal de Juiz de Fora.

Recebido em 25/1/99

Aceito para publicação em 6/12/99

Trabalho realizado no Hospital Geral do Andarai - RJ. Ministério da Saúde. 
zada, o óbito acontece em 14 a 25\% dos pacientes, geralmente causado pelas lesões associadas. O fato de serem infreqüentes, faz com que poucos estejam afeitos aos sinais e sintomas que conduzem ao diagnóstico e ao tratamento inicial adequados. Freqüentemente, o primeiro atendimento é feito por não especialistas, e as graves lesões associadas, que comumente estão presentes em outros órgãos, costumam dirigir as prioridades. $1,2,5,7,8$

$\mathrm{O}$ aumento atual no número de ferimentos da traquéia e dos grandes brônquios é justificado pela crescente violência urbana. A melhora no atendimento inicial ao traumatizado e os avanços obtidos na assistência ventilatória e nas técnicas de manutenção das vias aéreas livres, possibilitaram a identificação e o tratamento de um maior número de feridas traqueobrônquicas. ${ }^{9,10}$

Os autores fazem revisão da literatura, dando ênfase à etiologia, ao diagnóstico e ao tratamento das lesões da traquéia e grandes brônquios.

\section{ETIOLOGIA}

A posição anatômica ocupada pela árvore traqueobrônquica, normalmente, lhe confere uma proteção natural. A parte anterior encontra-se protegida pela mandíbula e o esterno, a posterior pela coluna vertebral e a lateral pelos arcos costais. Os ferimentos penetrantes são a principal causa das lesões, e a traquéia cervical, em virtude da sua maior exposição, costuma ser a mais atingida, correspondendo a cerca de $75 \%$ dos casos. ${ }^{9,11}$

Quando a lesão traqueobrônquica é provocada por ferimento penetrante, o diagnóstico costuma ser precoce. Enquanto que no trauma fechado, geralmente, é postergado e torna-se mais difícil. A ruptura da traquéia e dos brônquios, causada por trauma fechado, pode processarse de várias formas. Quase sempre, decorre de acidentes em alta velocidade com impacto direto na região anterior do pescoço ou na região esternal. ${ }^{12,13}$

$\mathrm{Na}$ dependência da intensidade do trauma sofrido, a compressão anteroposterior da caixa torácica provoca aumento no seu diâmetro transverso. A expansão lateral do gradil costal é acompanhada pelos pulmões, porém, a partir do momento em que a força de tração exercida ao nível da carina ultrapassa a elasticidade da árvore traqueobrônquica, a ruptura acontece. ${ }^{7,12,13}$ (Figura 1)

$\mathrm{Na}$ iminência de um trauma fechado, o indivíduo reage, instintivamente, com o fechamento súbito da glote. Entretanto, o mecanismo natural de defesa, traz como consequiência a súbita elevação da pressão na luz da árvore traqueobrônquica. A ruptura se processa, quando a compressão do ar no seu interior gera pressão superior à elasticidade traqueobrônquica. De acordo com a lei de Laplace, a pressão exercida por um gás no interior de um tubo fechado é proporcional ao seu raio. Esta é a razão, pela qual a traquéia e os grandes brônquios estão sujeitos a sofrerem lesões com mais freqüência, quando comparados ao restante da árvore brônquica. ${ }^{7,9,14}$

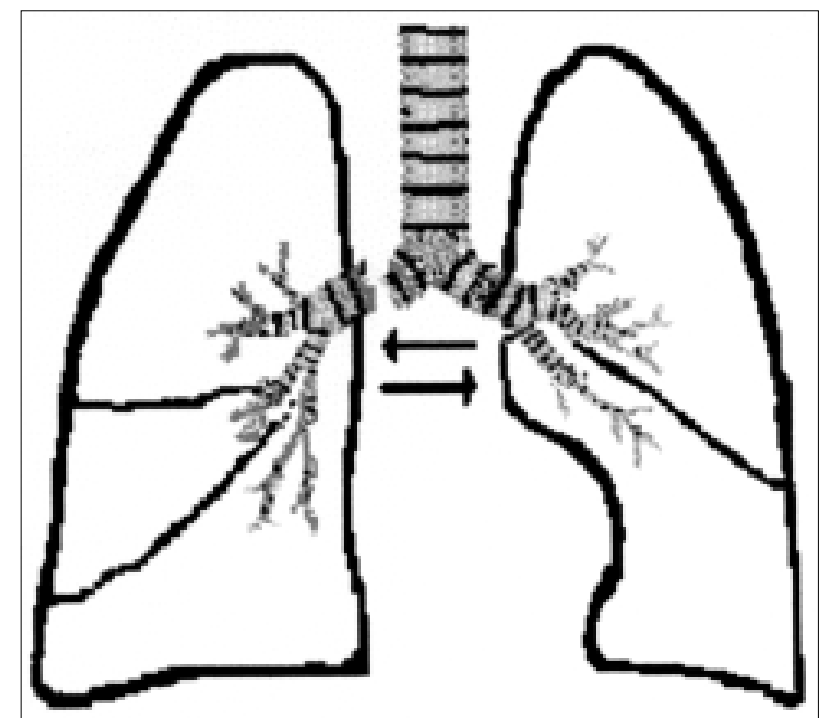

Figura 1 - Trauma fechado do tórax, causando compressão antero-posterior e rotura de brônquio.

A carina e a região da cartilagem cricóide, são os pontos com menor mobilidade na árvore traqueobrônquica. A desaceleração rápida, causada por colisões ou paradas bruscas de veículos, provoca movimento súbito de vaivém. Nestes locais fixos, o risco de ruptura é maior. Os estudos mostram que mais de $80 \%$ das lesões localizam-se nos brônquios principais, no limite de $2,5 \mathrm{~cm}$ próximos à carina. No trauma fechado de tórax, a incidência de lesões nos brônquios principais é similar. ${ }^{1,2,7} \mathrm{Em}$ uma revisão de 130 casos, o comprometimento entre o brônquio principal direito e o esquerdo foi semelhante e o acometimento simultâneo se deu em $2 \%$ dos pacientes. Os brônquios principais estavam lesados em $86 \%$ dos pacientes e na sua porção distal, em $9,3 \%$. ${ }^{10}$ A ruptura dos brônquios lobares é rara e os vasos pulmonares quase nunca são lesados. ${ }^{1,2}$

As feridas na traquéia cervical, provenientes de projéteis de armas de fogo e armas brancas, geralmente atingem a parede anterior ou lateral. É comum a lesão traqueal estar associada a outros órgãos, principalmente, o esôfago. Symbas et al. ${ }^{9}$, ao analisaram 18 feridas traqueais produzidas por projétil de arma de fogo, encontraram grandes lesões associadas em 12, sendo que, seis estavam localizadas no esôfago. Outras formas menos comum de lesões, são as provocadas por estrangulamento, eletricidade, queimadura e cáusticas. ${ }^{6}$

Iatrogenias podem ocorrer na árvore traqueobrônquica, seja durante a passagem de tubo orotraqueal simples ou, principalmente, de tubos de dupla luz do tipo Carlens e Robertshaw. ${ }^{1,15,16}$ Spaggiari et al. ${ }^{17}$, durante quatro anos, realizaram 800 intubações com tubos de dupla luz; ocorreram três $(0,37 \%)$ lacerações traqueobrônquicas. Todas foram tratadas cirurgicamente. A intercorrência também pode acontecer durante a realização de mediastinoscopia, ventilação mecânica, traqueostomia e endoscopia respiratória. O risco aumenta quando a endoscopia é para a retirada de corpo estranho. 1,16 
No trauma fechado de tórax, as rupturas traqueobrônquicas, geralmente, são transversas e costumam localizar-se entre os anéis cartilaginosos. Porém, a maioria das lesões longitudinais ocorre na parte membranosa ou na sua junção com a parede cartilaginosa (Figura 2). A combinação - lesão transversa e longitudinal, é denominada lesão complexa. Symbas et al. ${ }^{10}$, ao analisarem 189 casos publicados em língua inglesa, verificaram que 140 (74\%) das lesões eram transversas, 34 (18\%) longitudinais e $15(8 \%)$ complexas.

O retardo no diagnóstico da lesão traqueobrônquica, implica o surgimento de estenose parcial ou total, causada pelo tecido de granulação que se forma. A estenose

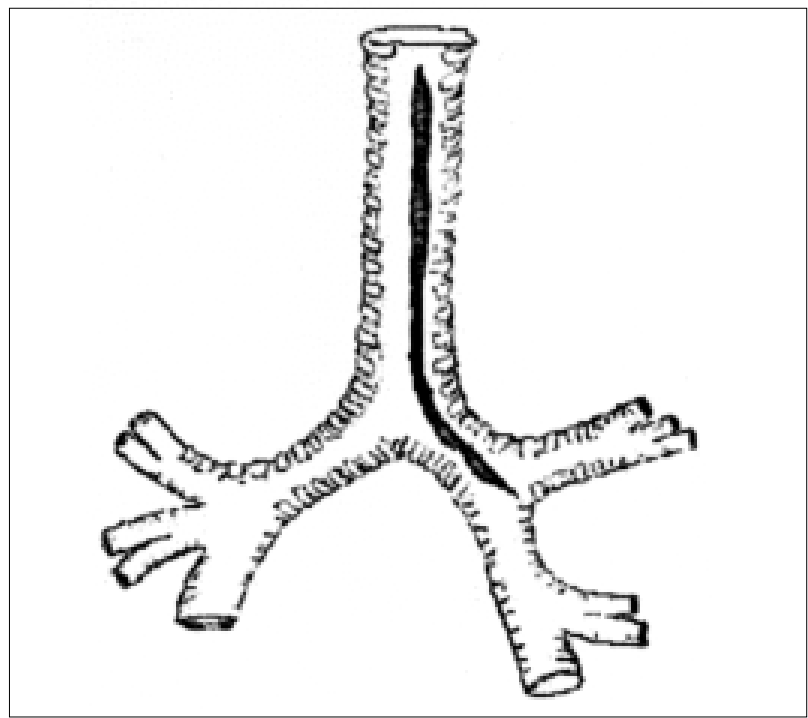

Figura 2 - Lesão na parte membranosa da traquéia e brônquio principal esquerdo. brônquica parcial, quase sempre, é seguida de infecções pulmonares de repetição e seqüelas pulmonares importantes. Na estenose completa ou secção total do brônquio, a sequiência evolutiva costuma ser: atelectasia, com preenchimento contínuo da luz brônquica por muco e absorção gradativa do ar. O pulmão tem a capacidade de permanecer quiescente e em boas condições por um longo período, mantendo-se atelectasiado, geralmente, sem infecção. $3,4,18$

A ruptura da traquéia ou grandes brônquios, nem sempre implica a laceração dos tecidos adjacentes. Com a integridade tecidual mantida, a ventilação pode processarse de maneira satisfatória, sem que ocorra escape de ar. Dessa forma, o diagnóstico torna-se difícil. Na sequiência, com o decorrer dos dias, a proliferação do tecido de granulação que se forma ao redor da lesão brônquica, conduz à obstrução total da sua luz. $4,7,14$

A traqueomalácia, surge a partir de múltiplas fraturas dos anéis traqueais, com potencial de provocar movimento paradoxal no local da lesão. Na inspiração, o segmento instável colapsa causando obstrução. Na expiração, de maneira inversa, ocorre protusão externa. ${ }^{4,7,14}$

A laceração, localizada no brônquio principal direito ou na parte distal do brônquio principal esquerdo, facilita de forma preferencial que o ar entre na cavidade pleural, constituindo, assim, o pneumotórax. Este, geralmente, possui características hipertensivas. ${ }^{119}$ ( Figura 3a)

Nos casos em que a traquéia os brônquios principais estão lesado, porém, com a pleura mediastinal íntegra, normalmente o ar disseca centralmente, formando enfisema mediastinal, cervical e subcutâneo que pode propagar-se até a face. ${ }^{1,19}$ (Figura 3b). Em 30\% dos casos publicados por Eijgelaar \& Heide ${ }^{19}$, não houve formação de pneumotórax, pois a pleura mediastinal manteve-se íntegra, mesmo após ter ocorrido laceração de brônquio ou de traquéia intratorácica.

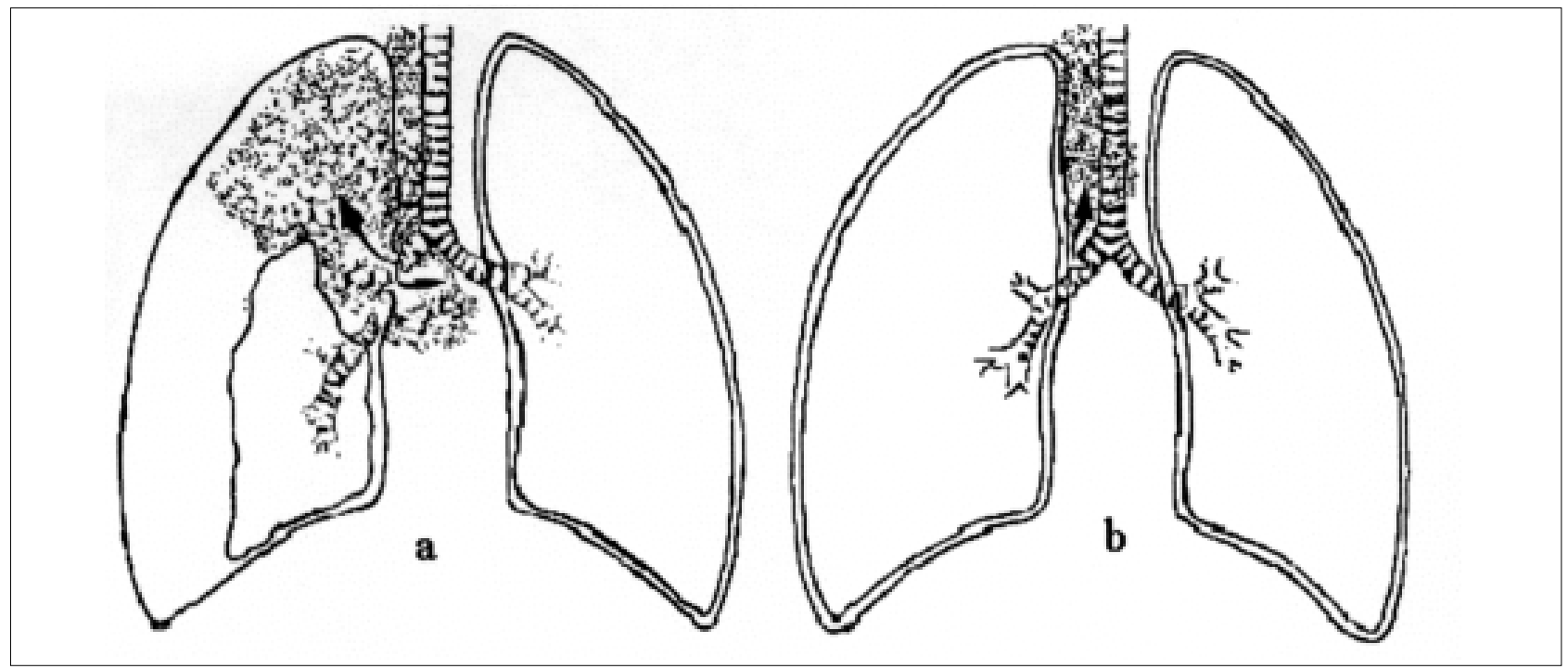

Figura 3 - a) Rotura de brônquio principal direito associado ao rompimento da pleura — pneumotórax e enfisema mediastinal. $b$ ) Rotura de brônquio principal direito com a pleura íntegra - enfisema mediastinal. 
Nos ferimentos penetrantes da traquéia, o esôfago, freqüentemente, também encontra-se lesado. A fístula traqueoesofágica, provocada por trauma fechado é rara, na maior parte das vezes ela se forma próximo à carina. Inicialmente ela pode passar despercebida por vários dias. Geralmente o politraumatizado é mantido em jejum, e a tosse, que constitui o principal sintoma, pode ser atribuída a outras lesões associadas. O diagnóstico torna-se fácil se houver a suspeita, pois a ingesta de líquidos e alimentos induz a tosse como resposta imediata. Na dependência do tamanho da fístula ocorre até a expectoração de partículas de alimento, o que praticamente define o diagnóstico. O mecanismo exato na formação da fístula entre a traquéia e o esôfago é desconhecido, porém, acredita-se que resulta da compressão da traquéia e do esôfago entre o esterno e a coluna torácica no momento do impacto. Aderências preexistentes entre a traquéia e o esôfago, e o sofrimento vascular causado pelo trauma, são fatores predisponentes que favorecem o surgimento da fístula. $\mathrm{Na}$ maioria dos casos, há formação de enfisema subcutâneo e/ou mediastinal. ${ }^{20,21}$

\section{MANIFESTAÇÕES CLÍNICAS}

Nas lesões traqueobrônquicas causadas por trauma fechado, geralmente encontramos outras lesões envolvidas. As mais comuns são as fraturas das costelas superiores, do esterno, clavícula e as contusões pulmonares. ${ }^{7,8,22,23}$

As manifestações clínicas das lesões traqueobrônquicas são variáveis. Dependem do intervalo decorrido entre o trauma e o diagnóstico, da localização e do tamanho da ferida, da integridade da pleura mediastinal e dos tecidos adjacentes e das lesões torácicas associadas. A dispnéia, nos seus vários graus, quase sempre está presente $\mathrm{e}$ o exame físico nem sempre expressa a agressão. ${ }^{2,11,12}$

É relativamente fácil o diagnóstico das feridas traqueobrônquicas causadas por agentes penetrantes. $\mathrm{O}$ trajeto do projétil de arma de fogo quase sempre é retilíneo, e pode ser definido pelos orifícios de entrada e saída ou então com o auxílio de radiografias, o percurso gera a suspeita de lesão traqueobrônquica. O mesmo ocorre com as lesões causadas por armas brancas que penetram nas proximidades da árvore traqueobrônquica. Os ferimentos abertos da traquéia, na região cervical, desde que não estejam tamponados com coágulos, produzem um ruído característico de sucção e eliminação de bolhas de ar pela abertura. Lesões concomitantes em outros órgãos são freqüentes, principalmente no esôfago, cuja integridade deve ser prontamente reconhecida. ${ }^{13,22}$ Kelly et al. ${ }^{21}$, encontraram feridas traqueobrônquicas associadas com o esôfago em $22 \%$ dos casos.

Quando os tecidos adjacentes à traquéia e aos brônquios mantêm-se íntegros, não ocorre vazamento de ar. Sob estas circunstâncias, o diagnóstico da lesão traqueobrônquica é dificultado, pois não há formação de pneumotórax e de enfisema mediastinal e/ou subcutâneo. A hipótese de ruptura surge quando ocorrem escarros sanguíneos, oriundos dos bordos lesados. ou hemoptise, geralmente proveniente de veias ou artérias brônquicas que sangram para o interior da luz traqueal ou brônquica. A secção dos anéis traqueais ou do complexo laringotraqueal, quase sempre cursa com insuficiência respiratória, tosse, estridor e alteração da voz. ${ }^{1,24,25}$

O rompimento da traquéia cervical induz a formação de enfisema subcutâneo, mais intenso nas regiões cervical e facial. Raramente ocorre enfisema mediastinal e pneumotórax. Lesões da traquéia torácica ou grandes brônquios, quase sempre evoluem com enfisema mediastinal, que costuma estender-se para o tecido celular subcutâneo localizado nas regiões torácica, cervical e facial. O rompimento da pleura mediastinal é acompanhado de pneumotórax, que dependendo da extensão da lesão, freqüientemente, torna-se hipertensivo. ${ }^{1,7,11,14,24,25}$

\section{ESTUDO RADIOLÓGICO}

As más condições clínicas, em que quase sempre se encontram os pacientes, e a precária qualidade do estudo radiológico, freqüentemente, não permitem conclusões definitivas quanto à integridade da árvore traqueobrônquica. Contudo, as radiografias simples do tórax e da região cervical, identificam com clareza, enfisema mediastinal, enfisema subcutâneo, pneumotórax, atelectasia e fraturas de arcos costais. Existindo secção total do brônquio principal, ocorre a queda do pulmão na cavidade pleural separado da sua inserção hilar. A radiografia convencional do tórax mostra, além do pneumotórax hipertensivo, a interrupção abrupta do ar no interior do brônquio, o que caracteriza a ruptura, e o bordo superior do pulmão colapsado abaixo da inserção hilar (sinal do hilo caído). A confirmação de fístula traqueoesôfagica, poderá ser feita pela ingesta de pequena quantidade de sulfato de bário diluído. Com a evolução do quadro, novas radiografias e a tomografia linear poderão detectar alterações que não eram evidentes logo após o trauma. $1,9,26$

A tomografia computadorizada helicoidal é capaz de fornecer dados adicionais e detectar as lesões traqueobrônquicas. A ressonância magnética produz imagens em múltiplos planos, com detalhes anatômicos da traquéia, carina, brônquios principais, vasos mediastinais e outras estruturas, sem necessidade do uso de contraste. Na fase tardia, a broncografia poderá ser de grande utilidade. 11,20

\section{BRONCOSCOPIA}

O exame endoscópico da árvore traqueobrônquica constitui-se no principal método de estudo. Define o diagnóstico, a topografia e o tamanho da lesão. Permite avaliar: a mobilidade das cordas vocais, o edema de glote e a existência de traqueomalácia. De acordo com os dados obtidos, faz-se a escolha do tratamento adequado - cirúrgico ou conservador. Com o auxílio do broncoscópio, podemos posicionar de forma correta o tubo orotraqueal na traquéia ou nos brônquios principais, principalmente quando a secção é total. 7,8,22,25,27

A limpeza da árvore traqueobrônquica é fator determinante na prevenção da formação de tampões, provocados principalmente, pelo acúmulo de secreções e/ou san- 
gue. Preferencialmente, o exame é realizado com o broncoscópio rígido. Com ele podemos ultrapassar a área lesada, manter ventilação pulmonar adequada e realizar intubação brônquica seletiva. Caso persistam dúvidas quanto à integridade da árvore traqueobrônquica, e o paciente necessite ser operado por outras causas, a broncoscopia deve ser efetuada antecedendo o ato operatório. ${ }^{7,22,25,27}$

Sob certas condições, a broncoscopia se impõe: nos grandes traumatizados de tórax, em presença de extenso enfisema mediastinal e/ou subcutâneo, atelectasia pulmonar, hemoptise e pneumotórax volumoso que persiste com grande escape de ar, mesmo após drenagem tubular correta da cavidade pleural. ${ }^{7,8,25}$

A broncoscopia é precisa e definitiva, quanto ao diagnóstico e à localização de fístula traumática entre o esôfago e a árvore traqueobrônquica. Nas comunicações pequenas, o azul de metileno poderá ser útil na sua comprovação, introduzido por meio de sonda nasogástrica no esôfago. A fístula é detectada pelo derramamento do corante na árvore traqueobrônquica, onde é observado com o broncoscópio. ${ }^{8,9}$

A endoscopia respiratória, quando realizada com normas bem estabelecidas e por cirurgião torácico com experiência em trauma, resulta em maior rendimento do método. Isto deve ser valorizado, pois cerca de $50 \%$ das lesões traqueobrônquicas não foram diagnosticados na primeira endoscopia. ${ }^{14,27}$ Symbas et al. ${ }^{9,10}$, propõem a realização da broncoscopia na própria sala de operações, já previamente equipada para o reparo imediato das lesões. Havendo trauma cervical associado, que impede a hiperextensão da cabeça, o uso do aparelho flexível se impõe.

Realizada na fase tardia, a broncoscopia permite avaliar a cicatrização das lesões, não diagnosticadas precocemente, e acompanhar as que são submetidas ao tratamento conservador ou cirúrgico. O seguimento, possibilita detectar a formação de granulomas que poderão ser ressecados por via endoscópica. A evolução com fibrose e estenose no local da sutura ou da lesão tratada de forma conservadora, eventualmente, será corrigida com dilatações. ${ }^{7,14,27}$

\section{TRATAMENTO}

Na presença de lesão traqueobrônquica, a atitude inicial consiste em assegurar uma via aérea livre, visando ao pronto restabelecimento da ventilação pulmonar. Ao mesmo tempo, ou logo em seguida, são analisadas a extensão da lesão e a coexistência de outros órgãos lesados. A presença de pneumotórax, exige drenagem pleural tubular fechada imediata. Esta torna-se obrigatória nos pacientes que serão submetidos à ventilação sob pressão positiva, independente do volume do pneumotórax. O borbulhamento intenso no frasco coletor de drenagem e o persistente escape de ar, denunciam fístula aérea de grande débito. ${ }^{6,8,10,16,27}$

Sabe-se que a correção das lesões traqueobrônquicas, quando praticada logo após o trauma, apresenta os melhores resultados. A via de acesso para abordagem cirúrgica dos brônquios e traquéia deve ser individualizada, sendo escolhida de acordo com a localização da lesão e de outras associadas porventura existentes. $5,9,10$
Normalmente a traquéia cervical é abordada por uma incisão paralela ao bordo interno do músculo esternocleidomastoídeo ou por incisão cervical transversa em colar, logo acima da fúrcula esternal. Caso seja necessário, em ambas, faz-se o prolongamento longitudinal em direção ao esterno. Embora, a incisão transversa permita boa exposição da laringe e da traquéia cervical, ela dificulta o acesso ao esôfago. Na eventual realização de esternotomia mediana longitudinal, como primeira opção, ou para reparo simultâneo de outras lesões, a traquéia, a carina e os brônquios principais poderão ser abordados por esta via. $7,8,9,28,29$

A toracotomia póstero-lateral direita, permite acessar à traquéia torácica em toda a sua extensão, ao brônquio principal direito e à porção proximal do brônquio principal esquerdo. Ao passo que, a toracotomia pósterolateral esquerda é utilizada para as lacerações localizadas distalmente no brônquio principal esquerdo. Por esta via, $o$ alcance ao brônquio principal esquerdo e principalmente, à traquéia, é dificultado pela presença da croça da aorta. $7,5,10,28$ Entretanto, Chen \& Ott ${ }^{30}$, mostraram que é possível, com uma toracotomia póstero-lateral esquerda, acessar o terço distal da traquéia até $5 \mathrm{~cm}$ acima da bifurcação traqueal. Mobilizaram distalmente o arco aórtico, a artéria subclávia e a aorta descendente, expondo dessa forma uma laceração de $4 \mathrm{~cm}$ localizada na parte distal e membranosa da traquéia (Figura 4).

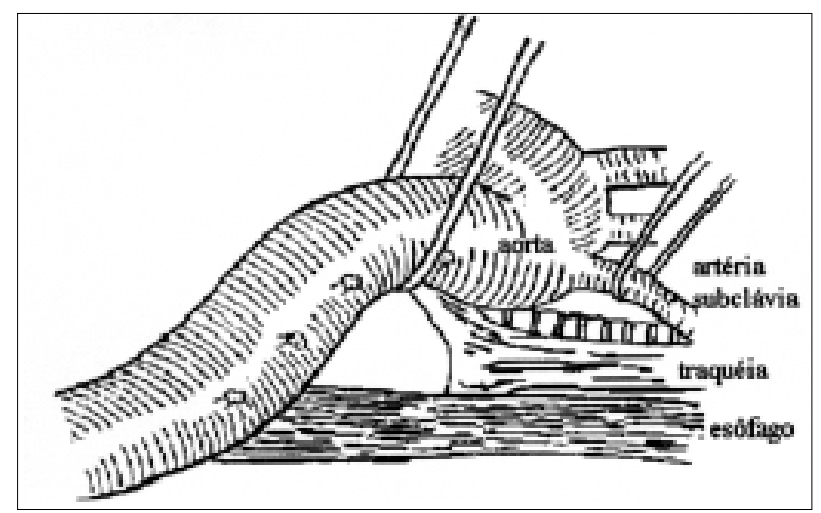

Figura 4-Lesão localizada na parte distal e membranosa da traquéia, abordada por toracotomia póstero-lateral. (Ann Thoracic Surg 1996;61:1819-1821).

O tratamento de escolha, nas lesões que não comprometem mais de um terço da circunferência da traquéia ou dos brônquios, geralmente é conservador. Contudo, quando a expansão pulmonar não se processa de imediato, mesmo após a drenagem pleural, a correção cirúrgica torna-se obrigatória. ${ }^{22}$ Symbas et al. ${ }^{9}$, trataram de forma conservadora dois pacientes com lesões pequenas na traquéia. Posicionaram o tubo orotraqueal abaixo da lesão com o balonete inflado, e assim o mantiveram por 24 a 48 horas, quando então o balonete foi esvaziado. Constatada a oclusão da ferida, recomendam a manutenção do tubo orotraqueal na posição por mais 24 horas. A partir do momento em que se estabilizam o enfisema subcutâneo e/ou 
o pneumomediastino, o tubo orotraqueal é retirado. A atitude conservadora deve ser criteriosa, pois quando equivocada causa graves sequielas. ${ }^{9}$

Os autores tiveram a oportunidade de acompanhar alguns casos em que a traqueostomia foi realizada de forma intempestiva e desnecessária, com a finalidade somente de tratar o enfisema subcutâneo ou como proteção da sutura brônquica e/ou traqueal. A traqueostomia deve ser realizada sempre abaixo da lesão, tem indicações precisas e aplica-se nos seguintes casos: a) nos ferimentos graves da laringe, em que ocorre formação de edema e hematoma significativos; b) para proteção da área de sutura na traquéia, quando está submetida à tensão excessiva e não inspira confiança; c) nos casos de dúvida ou paralisia das cordas vocais, causada pela lesão dos nervos laríngeos. ${ }^{13,6}$ Judice et al. ${ }^{13}$, realizaram traqueostomias em 11 de 17 pacientes com lesões na laringe.

Estando a ferida traqueal exposta, a introdução imediata da cânula através da própria lesão é a medida inicial correta. Ocorrendo secção total da traquéia, procedemos a intubação do segmento distal com o pronto restabelecimento da ventilação pulmonar. Na região cervical, o segmento traqueal distal costuma retrair-se para o mediastino superior. ${ }^{7}$ (Figura 5)

As lesões traqueobrônquicas, normalmente, são suturadas com fios sintéticos monofilamentares absorvíveis e, na falta destes, empregamos categute cromado. Aproximamos as bordas da ferida apenas o suficiente para impedir o escape de ar, sem prejuízo da vascularização. Os pontos são dados separadamente, e os nós deixados para fora da luz do órgão. A mobilização das estruturas traqueobrônquicas deve ser a estritamente necessária, o descolamento é realizado no plano posterior e anterior da tra- quéia. A manobra evita danos à irrigação sangüínea, originada nos vasos que penetram lateralmente na parede da traquéia. ${ }^{7,9,10,28}$ (Figuras 5 e 6)

Quando a lesão não envolve toda a circunferência da traquéia, apenas a sutura é realizada, caso seja necessário, precedida da regularização ou do debridamento das bordas laceradas. As feridas causadas por arma branca, geralmente, são lineares e localizam-se na face anterior da traquéia. Na maior parte das vezes, não há necessidade de ressecção de tecido e o fechamento é feito com pontos simples separados. De modo diverso, os ferimentos da traquéia e brônquios, causados por arma de fogo, costumam provocar destruição de tecido, o que muitas vezes obriga a realização de ressecção parcial e anastomose término-terminal. ${ }^{8,9,10}$

Nos casos de fraturas múltiplas dos anéis traqueais, estes devem ser ressecados e realizada anastomose término-terminal. Sempre que possível, as suturas devem ser protegidas com retalhos de músculo (exceção feita ao músculo intercostal), pericárdio, gordura pericárdica, pleura etc. Na cavidade pleural geralmente utilizamos a pleura parietal (Figura 7). Nas lesões simultâneas com o esôfago, a interposição de um retalho de tecido entre as suturas é obrigatório. Após a correção cirúrgica, a retirada do tubo orotraqueal deve ser precoce. A sua manutenção não se justifica, a não ser que coexistam outros fatores. A ressecção pulmonar raramente é necessária na fase aguda da lesão traqueal ou brônquica. $6,9,10$

O tratamento das lesões traqueobrônquicas, descobertas na fase tardia, e já acompanhadas de estenose brônquica total e atelectasia, pode variar desde broncoplastia até a pneumonectomia. A avaliação definitiva do parênquima pulmonar é macroscópica, feita durante o ato operatório. O grau de comprometimento do pulmão, deter-

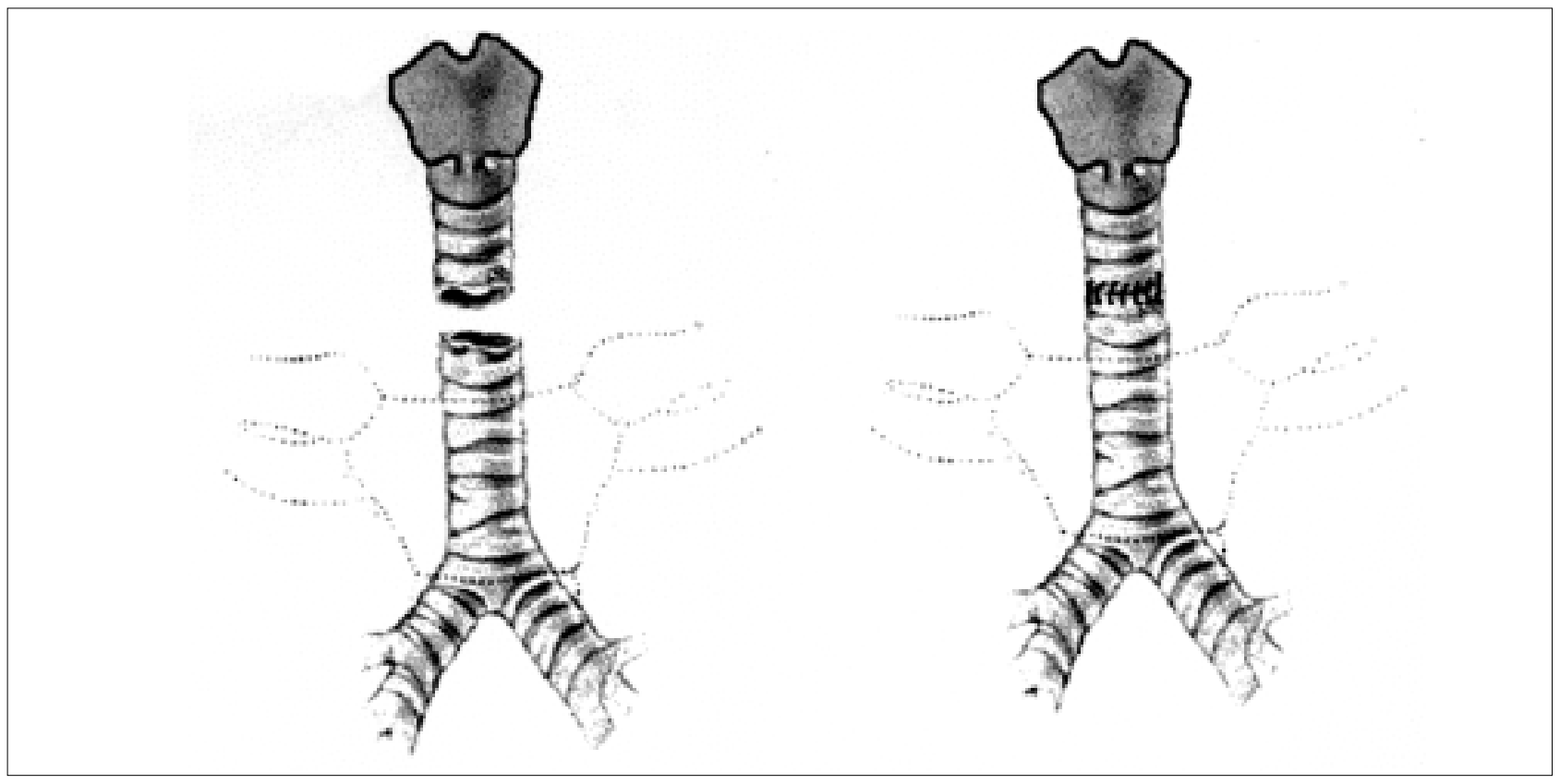

Figura 5 - Secção total da traquéia cervical. Regularização dos bordos e anastomose com pontos simples de fio absorvível. 


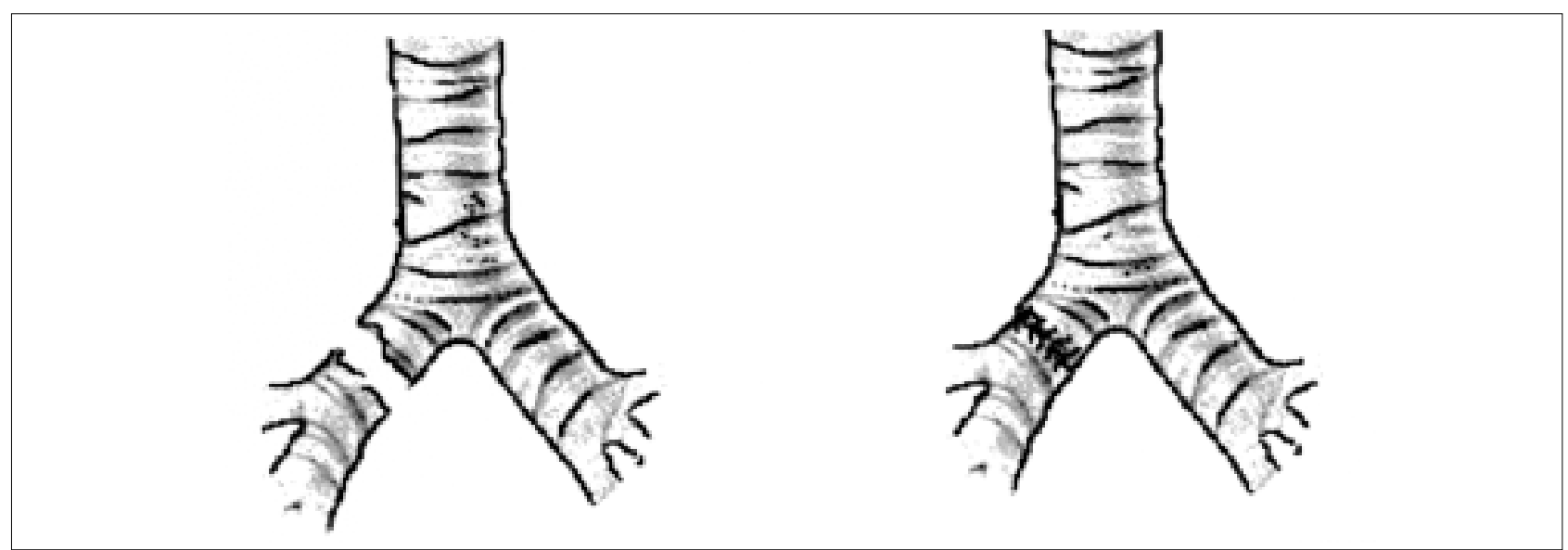

Figura 6-Secção total do brônquio principal direito. Anastomose com pontos simples de fio absorvível.

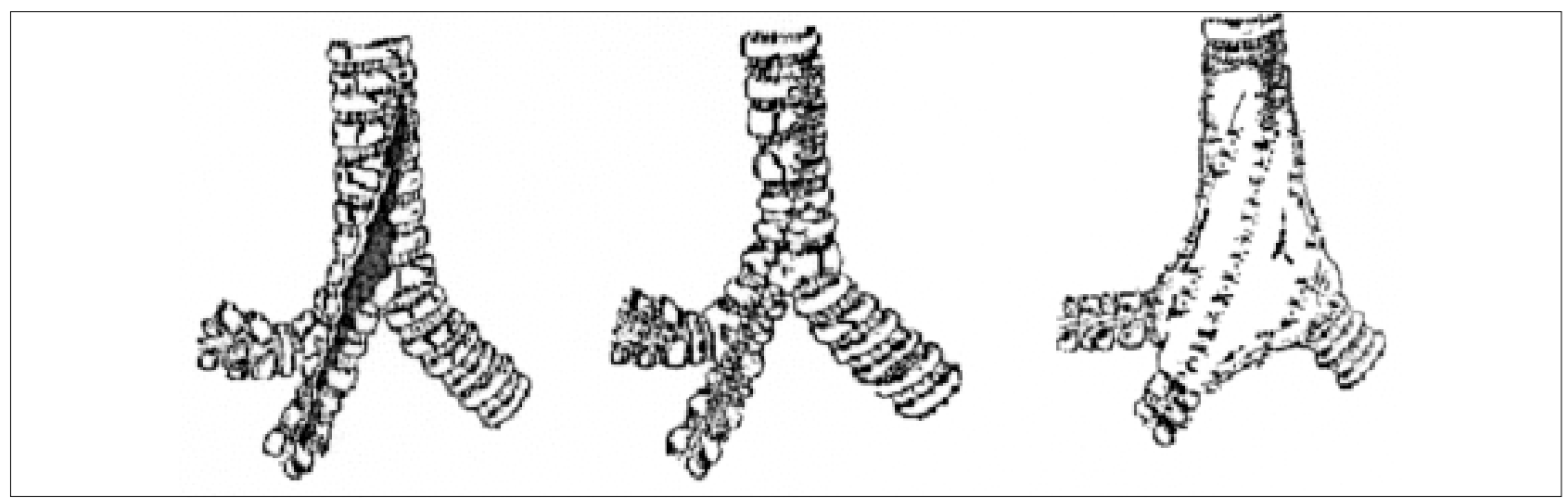

Figura 7 - Lesão traqueobrônquica extensa. Sutura e proteção com retalho de pleura partietal.

mina o tipo de operação. Estando o cirurgião convicto da viabilidade pulmonar e não havendo contaminação do muco, que normalmente preenche a árvore brônquica no pulmão atelectasiado, a broncoplastia pode ser realizada. Preenchidas essas condições, geralmente, o pulmão readquire suas funções, mesmo decorridos vários anos após a lesão. ${ }^{2}$
Finalmente, acreditamos que os principais fatores que interferem na evolução dos pacientes com lesões traumáticas da traquéia e brônquios são: alto índice de suspeição da lesão; recursos hospitalares disponíveis, além das radiografias convencionais, principalmente a broncoscopia, e a experiência do cirurgião que determina o tratamento mais adequado para o caso.

\begin{abstract}
Tracheobronchial injuries are rare but potentially life threatening. Their manifestations are variable and protean and misdiagnoses are common. Successful diagnosis and treatment often require a high level of suspection and unique surgical repairs to a given injury. Tracheal and main bronchial disruptions usually occurs after blunt chest trauma in the vicinity of the carina. Tracheobronchial disruptions occurred associated with high-energy impact trauma, and associated injuries were more common than they were to occur alone. Common presenting signs included subcutaneous emphysema, dyspnea, sternal tenderness, and hemoptysis. The most common were radiographic findings pneumothorax, pneumomediastinum, and clavicle or rib fractures. Rigid bronchoscopy and fiberoptic bronchoscopy were both highly accurate for the diagnosis but only when performed by trained thoracic surgeons. Emphasis has been placed on the importance of early diagnosis, to avoid the complications associated with a delayed repair. The etiological mechanisms, diagnostic and therapeutic aspects are reviewed and discussed.
\end{abstract}

Key words : Chest trauma; Tracheobronchial injury; Injuries of the trachea and major bronchi. 


\section{REFERÊNCIAS}

1. Collins JP; Ketharanathan V; McConchie I. Rupture of major bronchi resulting from closed chest injuries. Thorax 1973;28:371-375.

2. Guest JL \& Anderson JN. Major Airway Injury in Closed Chest Trauma. Chest 1977;72:63-66.

3. Hood RM; Sloan HE; Mich AA. Injuries of the trachea and major bronchi. J Thorac Cardiovasc Surg 1959;38:458-480.

4. Shaw RR; Paulson DL; Kee JL. Traumatic Tracheal Rupture. J Thorac Cardiovasc Surg 1961;42:281-297.

5. Bertelsen S \& Howitz P. Injuries of the trachea and bronchi. Thorax 1972;27:188-194.

6. Lee RB. Traumatic Injury Of The Cervicothoracic Trachea And Major Bronchi. Chest Surgery Clinics Of North America 1997;7:285-305.

7. Amauchi W, Birolini D, Branco PD, Oliveira MR. Lesões da Árvore Traqueobrônquica Por Traumatismo Torácico Fechado. Rev. Hosp. Clin. Fac. Med. S. Paulo 1983;38:130-136.

8. Rossbach MM, Johnson SB, Gomez MA, Sako EY, Miller OL, Calhoon JH. Management of Major Tracheobronchial Injuries: A 28-Year Experience. Ann Thorac Surg 1998;65:182-186.

9. Symbas PN; Hatcher CR; Vlasis SE. Bullet wounds of the trachea. J Thorac Cardiovasc Surg 1982;83:235-238.

10. Symbas PN; Justicz AG; Ricketts RR. Rupture of the Airways From Blunt Trauma: Treatment of Complex Injuries. Ann Thorac Surg 1992;54:177-188.

11. Mathisen DJ; Grillo H. Laringotracheal Trauma. Ann Thorac Surg 1987;43:254-262.

12. Chesterman \& Satsangi. Rupture of trachea and bronchi by closed injury. Thorax 1966;21:21-27.

13. Judice LF; Fernandes MFO; Mello LFP; Cordeiro PB; Lima O; Ramos LM; Biasi S. Major Airway Trauma. South American Journal Of Thoracic Surgery 1993;1:14-18.

14. Baumgartner F; Sheppard B; Virgilio C; Esrig B; Harrier D; Nelson RJ; Robertson JM. Tracheal and Main Bronchial Disruptions After Blunt Chest Trauma: Presentation and Management. Ann Thorac Surg 1990;50:569-574.

15. Massard G, Rougé C, Dabbagh A,Kessler R, Hentz JG, Roeslin N, Wihlm JM Morand. Ann Thorac Surg 1996;61:1483-1487.

16. Roxburgh JC. Rupture of the tracheobronchial tree. Thorax 1987;42:681-688.

17. Spaggiari L, Rusca M, Carbognani P, Solli P. Tracheal Laceration After Double-Lumen Intubation for Thoracic Procedures. Ann Thorac Surg 1998;65:1833-1842.

18. Mahaffey DE; Creech O; Boren HG; DeBakey M. Traumatic Rupture Of The Left - Main Bronchus Successfully Repaired Eleven Years After Injury. J Thorac Cardiovasc Surg 1956;32:312-331.

19. Eijgelaar JN \& Heide HVD. A reliable early symptom of bronchial or tracheal rupture. Thorax 1970;25:116-125.

20. Eastridge CE; Hughes FA; Pate FC; Richardson R. Tracheobronchial Injury Caused By Blunt Trauma. American Rev. Resp. Dis. 1970;101:230-237.

21. Kelly JP; Webbb WR; Moulder PV; Moustouakas NM; Lirtzman M. Management of Airway Trauma II: Combined Injuries of the Trachea and Esophagus. Ann Thorac Surg 1987;43:160-163.
22. Mills SA; Hudspeth AS; Myers RT; Salem W. Clinical spectrum of blunt tracheobronchial disruption illustrated by seven cases. J Thorac Cardiovasc Surg 1982;84:4958.

23. Taskinen SO; Salo JA; Halttunen PEA; Sovijãrvi ARA. Tracheobronchial Rupture due to Blunt Chest Trauma: A Follow-up Study. Ann Thorac Surg 1989;48:846849.

24. d'Odemont JP; Pringot J; Goncette L; Goenen M; Rodenstein DO. Spontaneous Favorable Outcome of Tracheal Laceration. Chest 1991;99:1290-1292.

25. Martinez MJ; Colonel L; Hotzman RS; Salcedo VM; Rinaldi RG. Successful repair of a transected intrathoracic trachea after chest trauma. J Thorac Cardiovasc Surg 1986;91:307-314.

26. Petterson C; Dselauriers J; McClish A. A Classic Image of Complete Right Main Bronchus Avulsion. Chest 1989;96:1415-1417.

27. Benfield JR. Traumatic Bronchial Rupture and Other Major Thoracic Injuries. Ann Thorac Surg 1990;50:523.

28. Grillo HC. Reconstruction of the trachea. Thorax 1973;28:667-679.

29. Lynn RB \& Iyengar K. Traumatic Rupture of the Bronchus. Chest 1972;61:81-83.

30. Chen RH \& Ott DA. Left Thoracotomy for Distal Tracheal Repair. Ann Thorac Surg 1996;61:1819-1821.

\section{ENDEREÇO PARA CORRESPONDÊNCIA:}

Dr. Giovanni Antonio Marsico

Serviço de Cirurgia Torácica 10 E/22

Av. Brigadeiro Trompowsky, S/N - Ilha do Fundão

21940-590 - Rio de Janeiro-RJ

Tel. (21) 562-2620

E-mail:marsicag@gbl.com.br 